\title{
Sintesis Magnesium Oksida (MgO) dari Dolomit Bangkalan dengan Metode Leaching
}

\author{
Devi Saputri, Lydia Rohmawati(a) \\ Jurusan Fisika FMIPA, Universitas Negeri Surabaya, Surabaya, Indonesia, 60231 \\ Email:(a)lydiarohmawati@unesa.ac.id
}

Diterima (02 Juni 2021), Direvisi (27 Juli 2021)

\begin{abstract}
Magnesium oxide $(\mathrm{MgO})$ is a ceramic material that has potential in the medical and industrial fields, where $\mathrm{MgO}$ can be obtained from natural dolomite which has a composition of $21.9 \% \mathrm{MgO}$ and 54.3\% CaCO3. However, $\mathrm{MgO}$ from dolomite has not been studied much so that this study was conducted with the aim of analyzing the effect of the holding time of calcination on the synthesized $\mathrm{MgO}$ phase. The $\mathrm{MgO}$ synthesis method uses the Leaching method, which is dissolving dolomite with $\mathrm{HCl}$ and stirring it at 75 ${ }^{\circ} \mathrm{C}$ for 45 minutes. After that, it is filtered where the results of the filtrate are added with ammonia until the solution reaches $\mathrm{pH} 12$ and a precipitate is formed. Furthermore, the precipitate was filtered and dried at 90 ${ }^{\circ} \mathrm{C}$ for 6 hours, and calcined at a temperature of $800{ }^{\circ} \mathrm{C}$ with a variation of the holding time of 4 hours, 8 hours, 12 hours, 16 hours, and 20 hours. The calcined powder was characterized by XRD and FTIR. The results showed that the optimum $\mathrm{MgO}$ main phase was formed at a holding time of 8 hours at a calcination temperature of $800{ }^{\circ} \mathrm{C}$ and had a nanocrystallite size of $20.12 \mathrm{~nm}$. FTIR results show that the $\mathrm{MgO}$ synthesized with a holding time of 8 hours has functional groups $\mathrm{Mg}-\mathrm{O}, \mathrm{Mg}-\mathrm{O}-\mathrm{Mg}, \mathrm{C}=\mathrm{O}$, alkene groups, and $\mathrm{H}-\mathrm{O}-\mathrm{H}$ in the wave number range of $4000 \mathrm{~cm}^{-1}-500 \mathrm{~cm}^{-1}$.
\end{abstract}

Keywords:MgO, leaching, holdingtime, synthesis.

Abstrak. Magnesium oksida (MgO) merupakan material keramik yang memiliki potensi dalam bidang medis dan industri, dimana $\mathrm{MgO}$ dapat diperoleh dari bahan alam dolomit yang memiliki komposisi $21,9 \% \mathrm{MgO}$ dan 54,3\% $\mathrm{CaCO}_{3}$. Namun $\mathrm{MgO}$ dari dolomit belum banyak dikaji sehingga penelitian ini dilakukan dengan tujuan untuk menganalisis pengaruh waktu tahan kalsinasi terhadap fasa $\mathrm{MgO}$ yang disintesis. Metode sintesis $\mathrm{MgO}$ menggunakan metode leaching yakni melarutkan dolomit dengan $\mathrm{HCl}$ dan diaduk pada suhu $75^{\circ} \mathrm{C}$ selama 45 menit. Setelah itu dilakukan penyaringan yang hasil filtratnya ditambahkan amoniak hingga larutan mencapai $\mathrm{pH} 12$ dan terbentuk endapan. Selanjutnya endapan tersebut disaring dan dikeringkan pada suhu $90^{\circ} \mathrm{C}$ selama 6 jam,dan dikalsinasi pada suhu $800^{\circ} \mathrm{C}$ dengan variasi waktu tahan 4, 8, 12, 16, dan 20 jam. Serbuk hasil kalsinasi dikarakterisasi X-Ray Diffraction (XRD) dan Fourier Transform Infra Red (FTIR). Hasil penelitian menunjukkan bahwa fasa utama $\mathrm{MgO}$ terbentuk optimum pada waktu tahan 8 jam suhu kalsinasi $800^{\circ} \mathrm{C}$ dan memiliki ukuran kristalit 20,12 nm. Hasil FTIR menunjukkan bahwa MgO hasil sintesis dengan waktu tahan8 jam memiliki gugus fungsi $\mathrm{Mg}-\mathrm{O}, \mathrm{Mg}-\mathrm{O}-\mathrm{Mg}, \mathrm{C}=\mathrm{O}$, gugus alkena, dan $\mathrm{H}-\mathrm{O}-\mathrm{H}$ pada rentang bilangan gelombang $4000 \mathrm{~cm}^{-1}-500 \mathrm{~cm}^{-1}$.

Kata kunci: $\mathrm{MgO}$, leaching, waktu tahan, sintesis. 


\section{PENDAHULUAN}

Magnesium oksida adalah mineral padat berwarna putih terbentuk dari ikatan ionik antara satu atom magnesium dan satu atom oksigen yang membentuk struktur kristal FCC [1]. Material MgO berukuran nano memiliki potensi yang lebih luas yakni dalam bidang industri dapat dimanfaatkan sebagai bakterisida, katalis, bahan keramik, remediasi dan absorben pada limbah [2]. Menurut Tang et al (2014) $\mathrm{MgO}$ dapat juga digunakan sebagai inhibitor dekomposisi aluminium titanata. Material tersebut juga dapat diaplikasikan dalam dunia medis yaitu agen antibakteri dan media pengobatan. Sebagian besar penelitian telah menggunakan $\mathrm{Mg}^{2+}$ untuk mensintesis $\mathrm{Mg}(\mathrm{OH})_{2}$ dan $\mathrm{MgO}$ nanopartikel [3]. Namun beberapa mineral alami seperti dolomit dan magnesit juga dapat digunakan sebagai sumber $\mathrm{Mg}^{2+}$ yang memiliki keuntungan lebih murah dan lebih cocok digunakan untuk industri dibandingkan dengan bahan komersial. Bahan alam yang dapat dimanfaatkan sebagai bahan utama pembuatan nanopartikel $\mathrm{MgO}$ adalah dolomit [4].

Dolomit dengan rumus kimia $\left(\mathrm{MgCa}\left(\mathrm{CO}_{3}\right)_{2}\right)$ merupakan batuan yang sejenis dengan batu kapur dan memiliki dua garam karbonat yaitu $\mathrm{CaCO}_{3}$ dan $\mathrm{MgCO}_{3}$. Secara teoritis dolomit murni mengandung 45,6\% $\mathrm{MgCO}_{3}$ atau 21,9\% $\mathrm{MgO}$ dan 54,3\% $\mathrm{CaCO}_{3}$ [5]. Pemanfaatan mineral dolomit yang terdapat di Indonesia hanya sebatas untuk keperluan pembuatan pupuk dolomit dan bata dolomit sebagai bahan bangunan sehingga memiliki nilai jual yang rendah [6]. Oleh karena itu untuk meningkatkan nilai jualnya, dolomit dapat diolah menjadi magnesium karbonat dan kalsium karbonat [4]. Proses penguraian magnesium karbonat dan kalsium karbonat pada dolomit dapat dilakukan dengan kalsinasi parsial. Kalsinasi parsial adalah proses penguraian kalsium karbonat dan magnesium karbonat dalam dolomit hingga diperoleh produk $\mathrm{CaO}$ dan $\mathrm{MgO}$ [7].

Rohmawatiet al (2019) telah melakukan penelitian preparasi $\mathrm{CaCO}_{3} / \mathrm{MgO}$ dari dolomit Bangkalan yang dimanfaatkan sebagai antibakteri pada rongga mulut. Pada penelitian tersebut preparasi $\mathrm{CaCO}_{3} / \mathrm{MgO}$ dilakukan dengan metode kalsinasi parsial, namun tidak memisahkan $\mathrm{CaCO}_{3}$ dan $\mathrm{MgO}$ pada dolomit [8]. Sehingga pada penelitian ini dilakukan pemisahan $\mathrm{CaCO}_{3}$ dan $\mathrm{MgO}$ dengan metode leaching untuk memudahkan proses sintesis $\mathrm{MgO}$. Metode leaching merupakan proses pelarutan dolomit yang menggunakan pelarut asam [9].

Li et al (2013), telah melakukan sintesis $\mathrm{MgO}$ dari dolomit dengan metode leaching menggunakan $\mathrm{HCl}$ sebagai pelarut. Metode leaching menggunakan pelarut $\mathrm{HCl}$ ini lebih efisien digunakan untuk memisahkan $\mathrm{MgO}$ dan $\mathrm{CaCO}_{3}$ dibandingkan dengan metode hidrotermal dan metode presipitasi yang memerlukan biaya mahal. Metode leaching juga hanya memerlukan alat dan bahan yang sederhana sehingga mudah untuk dilakukan. Serbuk hasil sintesis tersebut dikalsinasidengan variasi suhu $600^{\circ} \mathrm{C}$ $900^{\circ} \mathrm{C}$ selama 4 jam. Hasil penelitian tersebut menunjukkan bahwa fasa $\mathrm{MgO}$ terbentuk sempurna pada suhu kalsinasi $800^{\circ} \mathrm{C}$ [2].

Berdasarkan beberapa penelitian diatas, maka pada penelitian ini dilakukan sintesis $\mathrm{MgO}$ dari dolomit Bangkalan dengan metode leaching menggunakan pelarut $\mathrm{HCl}$ yang kemudian dikalsinasi pada suhu $800^{\circ} \mathrm{C}$ selama 4, 8, 12, 16, dan 20 jam untuk mendapatkan fasa $\mathrm{MgO}$ yang optimum pada suhu kalsinasi $800^{\circ} \mathrm{C}$. Hasil sintesis 
dikarakterisasi X-Ray Diffraction (XRD) untuk mengetahui pengaruh variasi waktu tahan terhadap fasautama $\mathrm{MgO}$ yang terbentuk dan dilanjutkan dengan karakterisasi Fourier TransformInfra Red (FTIR) pada sampel yang menghasilkan fasa $\mathrm{MgO}$ optimum untuk mengetahui gugus fungsi dari $\mathrm{MgO}$. Hasil penelitian ini diharapkan sampel yang disintesis dari dolomit menunjukkan fasa tunggal $\mathrm{MgO}$ dan nantinya dapat diterapkan sebagai material medis.

\section{METODE PENELITIAN}

\section{A. Alat dan bahan}

Alat dan bahan yang digunakan untuk sintesis $\mathrm{MgO}$ dari dolomite yaitu mortal alu, ayakan 200 mesh, beakerglass, gelasukur, $\mathrm{pH}$ meter, stirer, furnace, oven, dolomite Bangkalan, $\mathrm{HCl} 37 \%$ Merck, $\mathrm{NH}_{3}$ 25\% Merck, kertassaring, dan aquades.

\section{B. Preparasi Sampel}

Dolomit dihaluskan dan diayak menggunakan ayakan 200 mesh selanjutnya dikarakterisasi XRD untuk mengetahui komposisi fasa. Kemudian dikalsinasi selama 1 jam pada suhu $800^{\circ} \mathrm{C}$ untuk menguraikan $\mathrm{MgCO}_{3}$ menjadi MgO. Dolomit yang sudah dikalsinasi dikarakterisasi XRD untuk mengidentifikasi fasa yang terbentuk.50 gram dolomite hasil kalsinasi tersebut dilarutkan dengan $\mathrm{HCl}$ sebanyak $210 \mathrm{ml}$ dan diaduk pada suhu $75^{\circ} \mathrm{C}$ selama 45 menit. Larutan yang terbentuk disaring untuk mendapatkan filtrat, kemudian filtrate tersebut ditambahkan $\mathrm{NH}_{3}$ hingga pH12 dan terbentuk presipitat. Hasil presipitat dicuci dengan aquades sebanyak 3 kali dan dikeringkan pada suhu $90^{\circ} \mathrm{C}$ selama 6 jam. Selanjutnya dikalsinasi pada suhu $800^{\circ} \mathrm{C}$ dengan variasi waktu tahan $4,8,12,16$, dan 20 jam. Kemudian dikarakterisasi XRD untuk mengetahui fasa $\mathrm{MgO}$ optimum yang terbentuk pada variasi waktu tahan. Selanjutnya dilakukan karakterisasi FTIR pada sampel yang memiliki fasa $\mathrm{MgO}$ optimum untuk mengetahui gugus fungsi dari yang terbentuk.

\section{Teknik karakterisasi dan analisis data}

\section{X-Ray Diffraction (XRD)}

Karakterisasi XRD untuk mengetahui terbentuknya fasa utama pada sampel yang diuji. Alat XRD yang digunakan tipe XPert MPD systemdengan sumber radiasi $\mathrm{Cu} 35 \mathrm{~mA}, 40 \mathrm{kV}$ dengan panjang gelombang sebesar 1.54060 Ådan sudut 2 theta $0^{\circ}-80^{\circ}$. Sampel yang diuji berupa sampel serbuk. Hasil karakterisasi XRD dianalisis menggunakan sofwareMatch! untuk mengetahui fasa yang muncul pada setiap puncak, serta mengidentifikasi lebar peakdan intensitas maksimum dari fasa utama yang terbentuk. Persentase fraksi volume $\left(F_{v}\right)$ dari fasa yang terbentuk dapat dihitung dengan menggunakan rumus :

$$
F_{v}=\frac{I_{0}}{I_{\text {total }}}
$$

I merupakan intensitas fasa yang diinginkan dan $I_{\text {total }}$ adalah jumlah intensitas semua fasa yang muncul [10].

Ukuran kristalit $\mathrm{MgO}$ dapat ditentukan dengan pendekatan persamaan Scherrer yang dirumuskan pada Persamaan 2:

$$
D=\frac{K \lambda}{\beta \cos \theta}
$$

$D$ merupakan ukuran partikel, $K$ merupakan faktor bentuk dari kristal $(0,9-$ $1), \lambda$ merupakan panjang gelombang sinar X $(0,154056 \AA), \beta$ merupakan nilai dari Full Width at Half Maximum (FWHM) yang ditentukan dengan cara melihat nilai pelebaran kurva setengah puncak difraksi pada masing-masing bidang kristal di posisi $2 \theta$, dan $\theta$ adalah sudut difraksi (derajat) [11]. 


\section{Fourier Transform Infra Red (FTIR)}

Karakterisasi FTIR digunakan untuk mengidentifikasi gugus fungsi dan ikatan kimia yang dimiliki oleh material yang menyerap berkas cahaya inframerah pada panjang gelombang tertentu. Energi yang diserap sampel pada berbagai frekuensi sinar inframerah diteruskan ke interferometer dan diubah dalam bentuk interferogram. Alat karakterisasi FTIR yang digunakan merk Shimadzutype IR Prestige 21 dengan rentang gelombang 500-4000 $\mathrm{cm}^{-1}$. Berdasarkan uji karakterisasi tersebut didapatkan spektrum FTIR dari grafik hubungan Modus pemancar (\% T) dan bilangan gelombang $\left(\mathrm{cm}^{-1}\right)$, sehingga bilangan gelombang yang didapat dibandingkan dengan referensi jurnal untuk mengidentifikasi gugus fungsi pada sampel.

\section{HASIL DAN PEMBAHASAN}

\section{Hasil karakterisasi XRD}

Hasil karakterisasi XRD dolomit tanpa kalsinasi dan sesudah kalsinasi ditunjukkan pada Gambar 1. Berdasarkan analisis secara kualitatif dengan software Match! dolomit tanpa kalsinasi memiliki komposisi $\mathrm{MgO}$ dan $\mathrm{Ca}(\mathrm{OH})_{2}$ yang dominan dengan persentase fraksi volune masing-masing $45,9 \%$ dan $42,4 \%$. Persentase fraksi volume ini diperoleh dengan menghitung menggunakan Persamaan (2). Intensitas maksimum $\mathrm{MgO}$ terbentuk pada sudut $42,89^{\circ}$ sesuai dengan nomor PDF 96-1001095 [12]. Sedangkan intensitas maksimum $\mathrm{Ca}(\mathrm{OH})_{2}$ terbentuk pada sudut $34,71^{\circ}$ sesuai dengan nomor PDF 96-100-1769 [13]. Fasa lain yang terdapat pada dolomit yaitu $\mathrm{CaO}$ dan
$\mathrm{MgCO}_{3}$ dengan persentase fraksi volume masing-masing $7,80 \%$ dan 3,90\%.

Setelah dilakukan proses kalsinasi pada suhu $800^{\circ} \mathrm{C}$ selama 1 jam persentase $\mathrm{CaO}$ dan $\mathrm{MgO}$ meningkat, masingmasing persentase fraksi volume menjadi $53,2 \%$ dan $33,5 \%$. Intensitas optimum $\mathrm{MgO}$ terbentuk pada sudut $43,03^{\circ}$ sesuai nomor PDF 96-900-6748 [14]. dan intensitas optimum $\mathrm{CaO}$ terbentuk pada sudut $37,47^{\circ}$ dengan sesuai nomor PDF 96-720-0687 [15]. Peningkatan persentase $\mathrm{CaO}$ terjadi karena ketika proses kalsinasi dolomit $\mathrm{Ca}(\mathrm{OH})_{2}$ melepaskan $\mathrm{H}_{2} \mathrm{O}$ sehingga terurai menjadi $\mathrm{CaO}$ [6]. Sedangkan peningkatan persentase $\mathrm{MgO}$ disebabkan oleh $\mathrm{MgCO}_{3}$ yang terdekomposisi menjadi $\mathrm{MgO}$ dan $\mathrm{CaCO}_{3}$ pada suhu $500^{\circ} \mathrm{C}-700^{\circ} \mathrm{C}$. Kemudian pada suhu $750^{\circ} \mathrm{C}-900^{\circ} \mathrm{C}$ $\mathrm{CaCO}_{3}$ terdekomposisi menjadi $\mathrm{CaO}$ dan $\mathrm{CO}_{2}$ dengan demikian persentase $\mathrm{CaO}$ dan $\mathrm{MgO}$ semakin meningkat [7]. Hasil tersebut sesuai dengan penelitian Wulancahyanidkk (2020), yang mengungkapkan bahwa dengan suhu kalsinasi $800^{\circ} \mathrm{C}$ selama 1 jam dolomit memiliki fasaMgO dan $\mathrm{CaO}$ yang dominan [16].

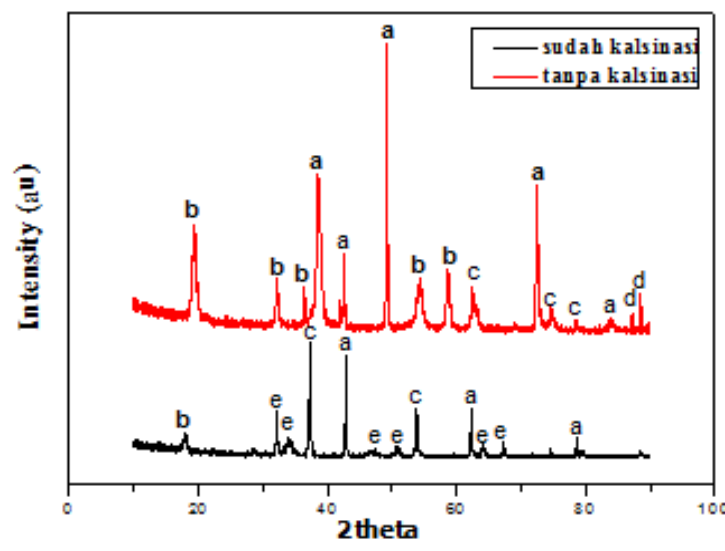

Gambar 1.HasilXRD dolomit sebelum dan sesudah kalsinasi, a $(\mathrm{MgO}), \mathrm{b}\left(\mathrm{Ca}(\mathrm{OH})_{2}, \mathrm{c}\right.$ $(\mathrm{CaO}), \mathrm{d}\left(\mathrm{MgCO}_{3}\right), \mathrm{e}\left(\mathrm{CaCO}_{3}\right)$. 
Tabel 1. Persentase komposisi dolomit

\begin{tabular}{ccc}
\hline Fasa & $\begin{array}{c}\text { Sebelum } \\
\text { kalsinasi }\end{array}$ & $\begin{array}{c}\text { Sesudah } \\
\text { kalsinasi }\end{array}$ \\
\hline $\mathrm{MgO}$ & $45,90 \%$ & $53,20 \%$ \\
$\mathrm{CaO}$ & $7,80 \%$ & $33,50 \%$ \\
$\mathrm{MgCO} 3$ & $3,90 \%$ & - \\
$\mathrm{Ca}(\mathrm{OH}) 2$ & $42,40 \%$ & $9,20 \%$ \\
$\mathrm{CaCO} 3$ & - & $4,10 \%$ \\
\hline
\end{tabular}

Hasil karakterisasi XRD dari sampel yang telah disintesis ditunjukkan pada Gambar 2. Analisis menggunakan softwareMatch! menunjukkan bahwa pada suhu kalsinasi $800^{\circ} \mathrm{C}$ menghasilkan sampel dengan fasa $\mathrm{MgO}$ yang dominan pada setiap variasi waktu tahan. Intensitas tertinggi $\mathrm{MgO}$ terbentuk pada sudut $42,96^{\circ}$. Fasa $\mathrm{MgO}$ lain terbentuk pada sudut $36,96^{\circ}, 62,36^{\circ}, 74,73^{\circ}$, dan $78,69^{\circ}$. Hasil tersebut sesuai dengan data PDF nomor 96-900-6748 [14]. Namun untuk sampel dengan waktu tahan 4 jam dan 8 jam, intensitas fasa $\mathrm{MgO}$ rendah dibandingkan dengan waktu tahan lainnya terutama pada sudut $74,73^{\circ}$. Intensitas $\mathrm{MgO}$ di sudut tersebut mulai meningkat pada waktu tahan 12 jam, 16 jam, dan 20 jam.

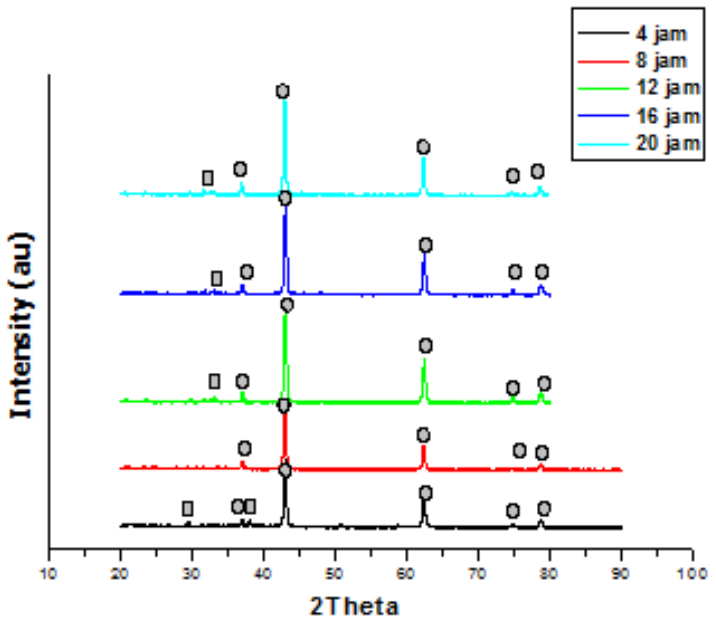

Gambar 2. pola difraksi $\mathrm{MgO}$ pada suhu kalsinasi $800^{\circ} \mathrm{C}$ dengan variasi waktu kalsinasi 4 , 8, 12, 16, dan $20 \mathrm{jam}, \mathrm{OMgO}, \square$ impuritas $\left(\mathrm{MgCa}\left(\mathrm{CO}_{3}\right)_{2}\right)$.
Tabel 2. Presentase fraksi volume fasa yang terbentuk pada masing-masing variasi waktu tahan

\begin{tabular}{ccc}
\hline $\begin{array}{c}\text { waktu } \\
\text { kalsinasi }\end{array}$ & $\mathrm{MgO}$ & $\mathrm{MgCa}\left(\mathrm{CO}_{3}\right)_{2}$ \\
\hline 4 jam & $98,02 \%$ & $1,98 \%$ \\
8 jam & $100 \%$ & $0 \%$ \\
12 jam & $97,23 \%$ & $2,77 \%$ \\
16 jam & $97,80 \%$ & $2,20 \%$ \\
20 jam & $95,37 \%$ & $4,63 \%$ \\
\hline
\end{tabular}

Fasa lain yang terbentuk yaitu $\left(\mathrm{MgCa}\left(\mathrm{CO}_{3}\right)_{2}\right)$ sebagai impuritas dengan peresentase berbeda-beda di setiap waktu tahan yang ditunjukkan pada Tabel 2. waktu tahan 4 jam terbentuk $\left(\mathrm{MgCa}\left(\mathrm{CO}_{3}\right)_{2}\right)$ sebesar $1,98 \%$ di sudut $29,41^{\circ}$ dan $37,98^{\circ}$, sedangkan waktu tahan 8 jam tidak menunjukkan adanya impuritas pada sampel. Namun impuritas tersebut kembali terbentuk pada waktu tahan 12, 16, dan 20 jam masing-masing di sudut $32,96^{\circ}, 31,66^{\circ}$, dan $32,04^{\circ}$. Hasil tersebut sesuai dengan data PDF nomor 96-900-1419 [17]. Persentase $\left(\mathrm{MgCa}\left(\mathrm{CO}_{3}\right)_{2}\right)$ stabil diatas $2 \%$ pada waktu tahan 12, 16, dan 20 jam. Dengan demikian fasa utama $\mathrm{MgO}$ terbentuk optimum pada waktu tahan 8 jam dengan suhu kalsinasi $800^{\circ} \mathrm{C}$.

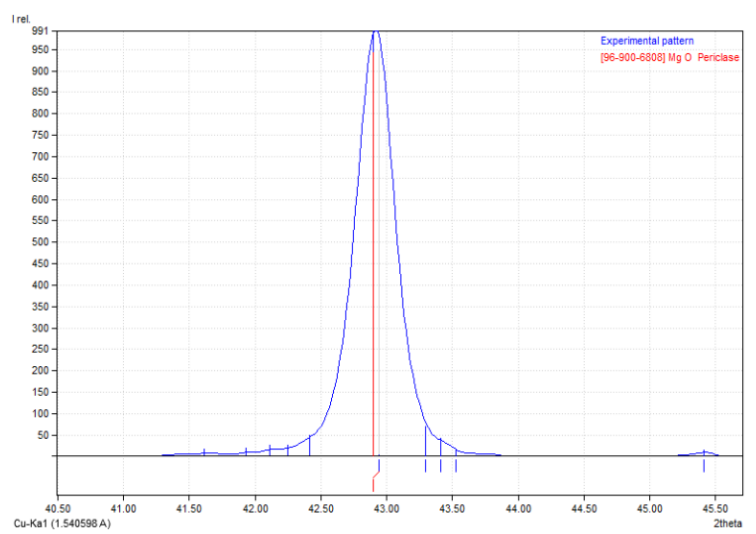

Gambar 3. Lebar dan sudut intensitas maksimum pada sampel dengan waktu tahan 8 jam 
Berdasarkan Gambar 3 dapat diketahui puncak maksimum $\mathrm{MgO}$ pada sudut 2 theta $42,90^{\circ}$ dengan nilai FWHM $0,20 \mathrm{deg}(0,0035$ radian $)$, sehingga dapat dihitung ukuran kristalit $\mathrm{MgO}$ menggunakan Persamaan (2) dan diperolehyang diperoleh sebesar 20,12 nm. Mantilaka et al (2014) menyatakan bahwa sampel yang memiliki ukuran kristalit kurang dari $100 \mathrm{~nm}$ merupakan nanokristalin [4]. Dengan demikian sampel $\mathrm{MgO}$ hasil sintesis dengan waktu tahan 8 jam termasuk memiliki ukuran nano.

\section{Hasil karakterisasi FTIR}

Gambar 4 merupakan hasil FTIR sampel dengan holding time8 jam yang menunjukkan fasa $\mathrm{MgO}$ optimum pada rentang bilangan gelombang $4000 \mathrm{~cm}^{-1}$ $500 \mathrm{~cm}^{-1}$. Spektrum $\mathrm{MgO}$ menunjukkan bahwa vibrasi $\mathrm{Mg}-\mathrm{O}$ terdapat pada puncak serapan bilangan gelombang $555,50 \mathrm{~cm}^{-1}$ yang mengindikasikan adanya magnesium oksida [18]. Vibrasi $\mathrm{Mg}-\mathrm{O}-\mathrm{Mg}$ terjadi pada bilangan gelombang $983,70 \mathrm{~cm}^{-1}$. Sedangkan pada bilangan gelombang 1478,12 $\mathrm{cm}^{-1}$ menunjukkan adanya gugus hidroksil. Vibrasi $\mathrm{C}=\mathrm{O}$ terjadi pada bilangan gelombang 1625,99 $\mathrm{cm}^{-1}$ yang memiliki struktur flavonoid serta menunjukkan adanya cincin aromatik [19]. Pada bilangan gelombang 2951,11 $\mathrm{cm}^{-1}$ terdapat guugus alkena. Pita serapan $\mathrm{H}-$ $\mathrm{O}-\mathrm{H}$ terjadi pada bilangan gelombang 3402,43 yang menunjukkan adanya absorbsi $\mathrm{H}_{2} \mathrm{O}$ [18]. Dengan demikian $\mathrm{MgO}$ hasil sintesis waktu tahan 8 jam menunjukkan karakteristik $\mathrm{MgO}$ yang memiliki gugus fungsi $\mathrm{Mg}-\mathrm{O}, \mathrm{Mg}-\mathrm{O}-\mathrm{Mg}$, $\mathrm{C}=\mathrm{O}$, gugus alkena, dan $\mathrm{H}-\mathrm{O}-\mathrm{H}$.
Tabel 3. Ikatan gugus fungsi material

\begin{tabular}{ccc}
\hline $\begin{array}{c}\text { Eksperimen } \\
\left(\mathrm{cm}^{-1}\right)\end{array}$ & $\begin{array}{c}\text { Referensi } \\
\left(\mathrm{cm}^{-1}\right)\end{array}$ & Jenis ikatan \\
\hline 555.50 & $548[18]$ & vibrasi Mg-O \\
983.70 & $850[20]$ & vibrasi Mg-O-Mg \\
1487.12 & $1450[21]$ & gugus hidroksil \\
1625.99 & $1635[19]$ & vibrasi C=O \\
2951.11 & $2739[21]$ & gugus alkena \\
3402.43 & $3461[18]$ & absorbsi H-O-H \\
\hline
\end{tabular}

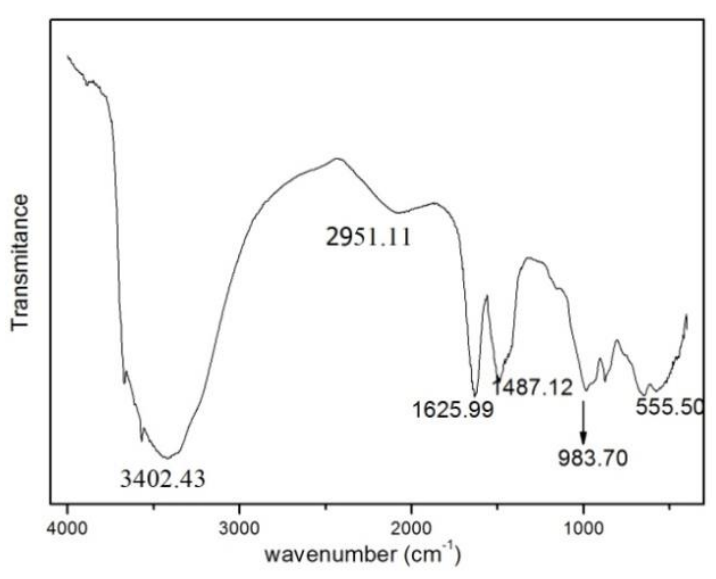

Gambar 4. Hasil FTIR MgO kalsinasi 8 jam

\section{KESIMPULAN}

Berdasarkan hasil penelitian dan analisis menggunakan software Match! diperoleh kesimpulan bahwa fasa utama $\mathrm{MgO}$ terbentuk optimum pada waktu tahan 8 jam dengan suhu kalsinasi $800^{\circ} \mathrm{C}$. $\mathrm{MgO}$ tersebut memiliki ukuran nano kristalin sebesar 20,12 nm. Hasil spektrum gelombang FTIR menunjukkan bahwa $\mathrm{MgO}$ dengan waktu tahan 8 jam memiliki gugus fungsi $\mathrm{Mg}-\mathrm{O}, \mathrm{Mg}-\mathrm{O}-\mathrm{Mg}$, $\mathrm{C}=\mathrm{O}$, gugus alkena, dan $\mathrm{H}-\mathrm{O}-\mathrm{H}$. 


\section{DAFTAR PUSTAKA}

[1] P. Alpionita and Astuti, "sintesis dan karakterisasi magnesium oksida ( mgo ) dengan variasi massa PEG-6000," J. Fis. Unand, vol. 4, no. 2, pp. 167-172, 2015.

[2] G. Li, Z. Li, and H. Ma, “Applied Clay Science Comprehensive use of dolomite-talc ore to prepare talc , nano- $\mathrm{MgO}$ and lightweight $\mathrm{CaCO}$ 3 using an acid leaching method," Appl. Clay Sci., vol. 86, pp. 145152, 2013, doi: 10.1016/j.clay.2013.09.015.

[3] Z. Tang and B. Lv, "MgO nanoparticles as antibacterial agent: preparation and activity," Brazilian J. Chem.Eng., vol. 31, no. 03, pp. 591-601, 2014.

[4] M. M. M. G. P. G. Mantilaka, H. M. T. G. A. Pitawala, D. G. G. P. Karunaratne, and R. M. G. Rajapakse, "Colloids and Surfaces A : Physicochemical and Engineering Aspects Nanocrystalline magnesium oxide from dolomite via poly ( acrylate ) stabilized magnesium hydroxide colloids," Colloids Surfaces A Physicochem. Eng. Asp., vol. 443, pp. 201-208, 2014, doi: 10.1016/j.colsurfa.2013.11.020.

[5] I. Maulana, S. P. Budio, and M. T. Hidayat, "Pengaruh Variasi Dolomit Material Lokal Kabupaten Bangkalan Sebagai Subsitusi Agregat Dalam Pembuatan Batako Terhadap Kuat Tekan Dan Absorbsi," J. Mhs. Jur. Tek. Sipil, vol. 1, no. 3, p. pp-1268, 2015.

[6] A. Royani and R. Subagja, "KLORIDA Extraction of Calcium from Calcined Dolomite Ore Using Hydrochloric Acid Leaching," J. Teknol. Miner. dan Batubara, vol. 15, no. September 2018, pp. 13-22, 2019, doi: 10.30556/jtmb.Vol15.No1.2019.92 4.

[7] E. Sulistiyono, F. Firdiyono, N. C. Natasha, and D. Sufiandi, "pengaruh ukuran butiran terhadap struktur kristal pada proses kalsinasi parsial dolomit," Maj. Metal., vol. 3, pp. 125-132, 2015.

[8] L. Rohmawati, S. P. Sholicha, S. P. S Holisa, and W. Setyarsih, "Identification of Phase $\mathrm{CaCO} 3 / \mathrm{MgO}$ in Bangkalan Dolomite Sand as An Antibacterial Substance," J. Phys. Conf. Ser., vol. 1417, p. 12001, 2019, doi: $10.1088 / 1742-$ 6596/1417/1/012001.

[9] Y. Abali, S. U. Bayca, K. Arisoy, and A. I. Vaizogullar, "Optimization of dolomite ore leaching in hydrochloric acid solutions," Physicochem. Probl. Miner. Process., vol. 46, no. 1, pp. 253-262, 2011.

[10]. Ross N. L., Reeder R. J., "Highpressure structural study of dolomite and ankeriteP $=3.70$ GPa", American Mineralogist 77, 412-421(1992)

[11] Masruroh, A. B. Manggara, T. Papilaka, and R. T. T, "Penentuan ukuran Kristal (crystallite size) lapisan tipis PZT dengan metode XRD melalui pendekatan persamaan Debye Scherrer," Erud. J. Educ. Innov., vol. 1, pp. 24-29, 2013. 
[12] H. G. Schimmel, J. Huot, L. C. Chapon, F. D. Tichelaar, and F. M. Mulder, "Hydrogen cycling of niobium and vanadium catalyzed nanostructured magnesium," $J$. Am. Chem. Soc., vol. 127, no. 41, pp. 14348-14354, 2005, doi: $10.1021 / \mathrm{ja} 051508 \mathrm{a}$.

[13] L. Desgranges, D. Grebille, G. Calvarin, G. Chevrier, N. Floquet, and J. -C Niepce, "Hydrogen thermal motion in calcium hydroxide: $\quad \mathrm{Ca}(\mathrm{OH}) 2, " \quad$ Acta Crystallogr. Sect. B, vol. 49, no. 5, pp. 812-817, 1993, doi: $10.1107 / \mathrm{S} 0108768193003556$.

[14] J. Zhang, "Effect of pressure on the thermal expansion of $\mathrm{MgO}$ up to $8.2 \mathrm{GPa}$," Phys. Chem. Miner., vol. 27 , no. 3 , pp. 145-148, 2000, doi: $10.1007 / \mathrm{s} 002690050001$.

[15] M. C. Verbraeken, E. Suard, and J. T. S. Irvine, "Structural and electrical properties of calcium and strontium hydrides," J. Mater. Chem., vol. 19, no. 18 , pp. $2766-$ 2770, 2009, doi: 10.1039/b820173k.

[16] E. Wulancahyani and L. Rohmawati, "Efektivitas Dolomit (CaCO3/MgO) Sebagai Pencegah Erosi Pada Enamel Gigi," J. Inov. Fis., 2020.

[17]. Ross N. L., Reeder R. J., "Highpressure structural study of dolomite and ankeriteP $=3.70$
GPa", American Mineralogist 77, 412-421(1992)

[18] M. Kandiban, P. Vigneshwaran, and I. V. Potheher, "Synthesis and characterization of $\mathrm{MgO}$ nanoparticles for photocatalytic applications," in Department of Physics, Bharathidasan Institute of Technology (BIT) Campus, Anna University, Tiruchirappalli, Tamilnadu, India, Conference Paper, 2015.

[19] R. Dobrucka, "Synthesis of MgO Nanoparticles Using Artemisia abrotanum Herba Extract and Their Antioxidant and Photocatalytic Properties," Iran. J. Sci. Technol. Trans. A Sci., vol. 42, no. 2, pp. 547-555, 2018, doi: 10.1007/s40995-016-0076-x.

[20] G. Balakrishnan, R. Velavan, K. M. Batoo, and E. H. Raslan, "Results in Physics Microstructure , optical and photocatalytic properties of $\mathrm{MgO}$ nanoparticles," Results Phys., vol. 16, no. November 2019, p. 103013, 2020, doi: 10.1016/j.rinp.2020.103013.

[21] M. Raghavendra, H. S. Lalithamba, B. S. Sharath, and H. Rajanaika, "Synthesis of $\mathrm{N} \alpha$ protected formamides from amino acids using $\mathrm{MgO}$ nano catalyst: Study of molecular docking and antibacterial activity," Sci. Iran., vol. 24, no. 6, pp. 3002-3013, 2017. 